\title{
Una aproximación a la escritura de babitación en Roma de Jorge Eduardo Eielson
}

Lic. Mariano Ramirez Moreno

El presente trabajo pretende reflexionar sobre la poética de babitación en roma (1976) de J.E. Eielson, a partir de una lectura de la crisis de la modernidad.

En este sentido, en un primer momento posicionamos la escritura del poemario citado dentro de una visión crítica de la neovanguardia. Luego, llevamos a cabo un análisis textual para desarrollar nuestra reflexión.

Lo que intentamos probar es que la escritura de babitación en roma revela una visión sediciosa de la vida moderna, afirmada en la vocación ctítica del yo poético como sujeto de la enunciación, constituyendo, respecto de esa misma crítica, una postura quínica ${ }^{1}$, semiotizada en la ironia y en lo grotesco de la estética del poemario.

La vocación crítica de ese yo poético, un ego que se difumina o fragmenta en el acto enunciativo, sitúa al lector dentro de un espacio urbano en el que prima la decadencia y la deformidad de una sociedad que a fuerza de modernidad ha perdido su "aura", su densidad irrepetible, su ser en sí, convirtiêndose en un lugar de desencanto y de "repetición" vacia de las experiencias estéticas. Los actantes que aparecen casi siempre se hallan en un grado crecido de orfandad, quizá solo el cuerpo humano que, presentándose inútil y desprovisto de toda densidad idealista, recupera en la escritura el aura de la materia humana. Este efecto poético es alcanzado a través del uso de recursos propios de la vanguardia.

La poesía de J.E. Eielson, como la han afirmado sus críticos más importantes ${ }^{2}$, fluye a través del neosimbolismo, la neovanguardia y la postneovanguiardia; es decir, entre la sugerencia y la sensación del simbolismo, y la ruptura y el montaje vanguardista. Su estética, o su poética, se instala entonces en la frontera de la modernidad, entendiendo a ésta como un conjunto de discursos

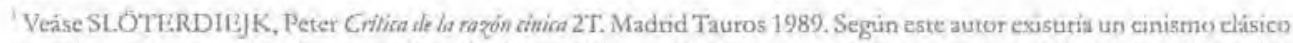
llamado quinismo, un tipo de pensamiento/acción nacido en Grecia que reaccionó contra la seriedad de la racionalidad autoritaria, absoluta e idealista, no material, de la filosófía platónica. Su representante más importante fue Diógenes de Sinope.

'Vérse FERNANDEZ COZMAN Camilo Las buellas del aure. La poétisa de f.E. Eielson. Capitulo 1.Editorial Lanoumericana, Lima 1996
} 
articulados alrededor de determinados metarrelatos que afirman un locus de enunciación, representado por la idea de sujeto cognoscente. Este sujeto, en el campo de la producción poética de la lírica moderna, se concentra en la imagen del yo poético como portador de un saber-poder específico y propio ${ }^{4}$. En el caso de la vanguardia, la imagen del poeta se halla inmersa dentro de la problemática del lenguaje, siendo este último el sujeto de dicha lírica ${ }^{5}$.

Así, la escritura de Eielson en babitación en roma, se hallaría, dentro de la periodificación de Fernández Cozman ${ }^{6}$, en la etapa neovanguardista del poeta, debido a que "evidencia un discurso fragmentado". Este hecho introduce a su escritura dentro de una visión de frontera de la modernidad que asumiría el discurso crítico de la misma.

Sobre el tema que nos anima, según Peter Bürger", la poética de vanguardia tuvo como aspiración principal romper con la institución del arte en tanto que ésta se hallaba inmersa dentro de los cánones de una cultura "agotada".

De acuerdo a la lectura de Bürger, la vanguardia no desarrolló un estilo _entendiendo a éste como el conjunto de medios artísticos ligados a normas estilísticas, "en el cual_aunque mediadas_se reflejan las normas sociales"_pues los movimientos vanguardistas habrían "convertido en principio la disponibilidad de los medios artísticos de las épocas pasadas"; luego: "Sólo la disponibilidad universal (de los medios artísticos) hace general la categoría de medio artístico". Así, no existiría un estilo dadaísta o un estilo surrealista, sino sólo posteriormente a ellos como consecuencia de su naturalización histórica y cultural.

De ahí que la pretensión revolucionaria _es decir, la búsqueda (infructuosa) de lograr la conjunción del arte con la praxis vital a través de la destrucción de la institución del arte_de los movimientos vanguardistas superaria cualquier propuesta anterior que haya implicado cierta postura crítica. Bürger la denomina "critica inmanente al sistema", pues la Vanguardia proponía la "autocrítica [total] del arte"; es decir, la completa destrucción de la institución del arte:

\footnotetext{
'CASULLO, Nicolás (Compilador) El debale nodernidad-posmorlennidad Buenos Aires: Puntosur Ed, 1991

"FRIEDRICH, Hugo La estrictura de la livieo moderna Barcelona Seix Barral 1974

"BUURGER, Peter Teoria de la vanguardia. Madrid, Taurus 1987; Mignolo, W. "La figura del poeta en la lírica de vanguardia" Revitta Ibervamuricanta $\mathrm{N}^{\circ} 118-119$ Encto-Junio 1982 pp $131-148$

- C. FERNÁNDEZ considera que existen tres grandes etapas en la producciōn eislsoniana: una neosimbolista representada por Reinos, una segunda neovanguardista, representada por Habilación en Roma y la tercera posvangaurdiasta enla que sedistingue Pbx:

'FERNANDEZ COZMAN, Camilo Op. Cit.p. 19

'BÜrger, Peter Op.Cit.
} 
Con el concepto de institución arte me refiero aquí tanto al aparato de producción y distribución del arte como a las ideas que sobre el arte dominan en una época dada y que determinan esencialmente la recepción de las obras. La vanguardia se dirige contra ambos momentos: contra el aparato de distribución al que está sometida la obra de arte, y contra el status del arte en la sociedad burguesa descrito por el concepto de autonomia?

Esta pretensión de devolver el arte a la praxis vital, sin embargo, no significó el alejamiento de la vanguardia del proceso histórico de la modernidad, sino, por el contrario, el movimiento se convertiría pronto en un estadio más en el proceso histórico de las categorías estéticas. Es decir, deducimos que, de la naturalización histórica y cultural de la vanguardia, cualquier intento estético posterior que retome sus pretensiones no se convertirá en posibilidad revolucionaria, sino casi únicamente en una moda. Asi, las obras de la neovanguardia resultarán solamente efectos de un "estilo" dentro del proceso del arte actual.

Es ese sentido, la vanguardia, a su pesar, habría desarrollado un determinado estilo que los creadores de los años siguientes pueden coget, usar y transformar como cualquier otro. Este estatuto de uso, convierte el hacer estético neovanguardiasta, en el caso de la poética de babitación en roma, en un recurso de elaboración cognitivo en el que regiria una voluntad de téplica, de resistencia contra una cultura opresiva y logocéntrica, a través de una operación inversa en la que el dolor, lo grotesco y el patetismo encubren/descubren una revaloración libertaria del cuerpo y la belleza; pues los elementos utilitarios de la vanguardia manifestados en el texto no asumen la voluntad política contra la institución arte, sino contra la autoridad de una cultura urbana industrializada que habría aniquilado la autenticidad y la esperanza:

\author{
Damas y caballeros \\ las ventanas abiertas \\ ya no dan al cielo \\ como hace tanto tiempo \\ ni la pálida luna \\ que todos conocimos \\ alumbra el corazón \\ delos pastores
}

\footnotetext{
'BUTGER, Ibidem. p. 62
} 
una pared muy alta

de cemento ciertamente

y una columna de humo

ocupan el lugar...

poemo para destrair de inmediato... 1976 p.199

La no revolucionaridad de la neovanguardia le sirve a Eilson para construir un discurso aparentemente hundido en la inmovilidad del abatimiento, aparentemente consumido por el pesimismo y reducido a la convencionalidad estetizante del arte contemporáneo, guardando, sin embargo, en el otro fondo de sus versos, una violenta y formidable resistencia cultural del cuerpo, la belleza y la alegría de la vida. De esta manera en la escritura de babitación..., el aporte de Eielson se hallaría en el plano del sentido ético de su discurso (esta postura se confirmaría en los textos posteriores a babitación en roma $)^{10}$. Por ejemplo, en el poema "junto al tíber la putrefacción emite destellos gloriosos" vemos una vocación crítica contra la institución del arte, pero esta crítica se hallaría dominada por un hastio superior a la revolución vanguardista, un hastio que tiene que ver ya no con el arte, sino con la vida misma:

heme aquí juntando
palabras otra vez
palabras aún
versos dispuestos en fila
que anuncien brillantemente
con exquisita fluorescencia
el nauseabundo deceso
del amor
millares y millares
de palabras escritas
en un water-close
mientras del cielo en llamas
de roma
cuelgan medias y calzoncillos
amarillos
cómo puedo yo escribir
y escribir tranquilamente
y a la sombra
de una cúpula impasible

\footnotetext{
${ }^{17}$ Una nocbe oscara del cuerpo, tumbién en Plyx; cuyo universo imaginado semiotiza el espacio oculto del cuerpo, recuperindolo de la memoria y trasladando al lector a una intimidad inquetante y reveladora.
} 
de una estatua

que sonríe

y no salir gritando

por los barrios horrendos

de roma

y lamer las llagas de un borracho...

Eielson construye un discurso ético en el que la impasibilidad horrenda de lo inauténtico pareciera predominar sobre toda esperanza. Pero lo interesante es la forma cómo lleva a cabo esta vocación. El uso de una retórica que fragmenta la presencia del ego y destruye la continuidad de la racionalidad lógica, quebrando el lenguaje bajo el imperio de la desintegración del significante dentro de una "literatura autocrítica que cuestiona su propio estatuto discursivo"11.

Así, será la ironía, lo patético y lo grotesco, las formas cómo esta escritura reaccionará, como resistencia y rebeldía contra la opresión y la represión, aportando una visión quinica del mundo, acercándose a aquello que los críticos han llamado postmodernidad, construida a partir de una ética del rechazo de la seriedad y el autoritarismo del discurso moderno.

Según Pavao Pavlecic ${ }^{12}$, la modernidad en las artes se establecería a partir de un incisivo cuestionamiento del pasado, tratando de negarlo o utilizándolo para afirmar un discurso nuevo. Así, la modernidad literaria operaría a partir de la ocupación intertextual de una obra en particular del pasado con el objetivo de sumar nuevos significados a un nuevo texto. Por tanto, la modernidad, a través de un hacer paródico, instaura un saber institucionalizado.

Por el contrario, en la era del saber postmoderno, el arte se veria quebrado por la intromisión de una estética básicamente descentrada que articularía los discursos del pasado, en busca de un estado eufórico y complaciente, sin la voluntad de progreso ni cambio que la caracterizaba en la modernidad. Es esto lo que hace babitación... respecto de la Vanguardia.

Pues en el ámbito de la vida, este cambio de perspectiva podria traer consigo problemas para la convivencia social y la legitimidad política y cultural. Sin embargo, dicho cambio vendría a ser el resultado de la propia inoperatividad de la modernidad y, fundamentalmente, del fracaso de la ilustración. Fue ella, a

\footnotetext{
"FERNANDEZ COZMAN. Op. Cit.p.102

"PAVLICIC, Pavao. "La intertextualidad moderna y posmoderna", Crilerios. 30, VIL-XII. La Habana 1991
} 
través de la sociedad burguesa, la que tendió por primera vez los puentes entre el saber de arriba y el saber de abajo, "pretendiendo fundar íntegramente su imagen del mundo sobre el realismo, [como consecuencia] los extremos se van entrelazando cada vez más" ${ }^{13}$.

Este fracaso es notable en cuanto echamos una mirada al estado de cosas de la última década del milenio. Nada de las promesas universalistas de la ilustración parece sostenerse en un mundo cada vez más hundido en el cinismo. El cinismo moderno vendría a ser el resultado involuntario de las pretensiones de un proyecto sustentado básicamente en la razón instrumental.

El cínico moderno "es un integrado antisocial que rivaliza con cualquier hippie en la subliminal carencia de ilusiones" ${ }^{14}$; esta carencia de ilusiones marca una característica fundamental del estado general de la cultura postmoderna.

Se entiende mejor el cinismo moderno si lo contraponemos, como hace Sloterdijk, al quinismo griego. Básicamente, el quinismo se constituye en un rechazo del pensamiento del idealismo duro, que opone al cuerpo, a la materia, un saber abstracto e inalcanzable, un saber irrealizable en el que es imposible una "encarnación material". Así, el quinismo se sostiene sobre el fundamento auroral de la filosofia griega, olvidado y deleznado por los enormes y complejos sistemas de pensamiento posteriores:

En el filósofo, el hombre del amor a la verdad y de la vida consciente, vida y doctrina tienen que estar siempre de acuerdo. El centro de toda doctrina es lo que de ella materializan sus seguidores. (...) si el filósofo es llamado a vivir lo que dice, entonces su tarea es, en un sentido crítico, mucho mayor: la de decir lo que vive. (...) Una separación de persona y cosa, teoría y praxis no es considerable en absoluto (...) Encarnar una doctrina significa convertirse en su medio $^{15}$.

Este fundamento, en medio de las abstracciones del idealismo y la cultura construida a partir de él, se convierte en una insolencia. El quinismo es pues insolencia. Luego:

\footnotetext{
"SLOTERDIJK, Peter Critica de la napón cinica 2T. Madrid Tauros 1989 Pp,280

"Ibidem p, 33

${ }^{15}$ Tbidem p. 148
} 
Desde que la filosofía, sólo de una manera hipócrita, es capaz de vivir lo que dice, le corresponde a la insolencia decir lo que vive. En una cultura en la que los idealismos endurecidos convierten las mentiras en "formas de vida", el proceso de verdad depende de si hay personas que sean suficientemente agresivas y libres ("desvergonzadas"), para decirla verdad ${ }^{16}$.

Sin embargo,

Cuando los poderosos, por su parte empiezan a pensar quínicamente; cuando conocen la verdad sobre sí mismos y, a pesar dè ello, "continúan" obrando de igual manera, entonces completan de una manera perfecta la definición moderna de cinismo ${ }^{17}$.

Esta definición será: cinismo: "falsa conciencia ilustrada".

Por tanto, el quinico es aquel que enfrenta, con ironía y jovialidad, la seriedad de un saber institucionalizado que pretende ocultar la contradicción y la diferencia. Un hombre y su estremecimiento, su naturaleza. Como un perro. El quinismo es la reacción contra el saber serio, autoritario y universalista. El cínico moderno, en contraposición, es aquel que sufre sin remedio el ocultamiento del fracaso de la ilustración. Se produce entonces en él un malestar atribuido a la cultura:

Psicológicamente se puede comprender al cínico de la actualidad como un caso límite del melancólico, un melancólico que mantiene bajo su control sus sintomas depresivos y, hasta cierto punto, sigue siendo laboralmente capaz. Pues, en efecto, en el caso del moderno cinismo la capacidad de trabajo de sus portadores es un punto esencial... a pesar de todo y después de todo. (...) Una cierta amargura elegante matiza su actuación. Pues los cínicos no son tontos y más de una vez se dan cuenta, total y absolutamente, de la nada a la que todo conduce. Su aparato anímico se ha hecho, entre tanto, lo suficientemente elástico como para incorporar la duda permanente a su propio mecanismo como factor de supervivencia. Saben lo que hacen, pero lo hacen porque las presiones de las cosas y el instinto de autoconservación, a corto plazo, hablan el mismo lenguaje y les dicen que así tiene que ser. De lo contrario otros lo

\footnotetext{
${ }^{14}$ Ibidem p.149

${ }^{17}$ Ibidem.

"Tbidemp.34
} 
harán en su lugar y, quizá, peor. De esta manera, el nuevo cinismo integrado tiene de sí mismo, y con harta frecuencia, el comprensible sentimiento de ser víctima y, al mismo tiempo, sacrificador. Bajo esa dura fachada que hábilmente participa en el juego, porta una gran cantidad de infelicidad y necesidad lacrimógena fảcilmente vulnerable. Hay en ello algo de pena por una "inocencia perdida", de sentimiento por un saber mejor contra el que se dirige toda actuación y todo trabajo ${ }^{1 \mathrm{t}}$.

Este malestat se traduce en una serie de acciones y circunstancias neuróticas en busca de goce que, sin embargo, siempre culminan en un estado de absoluta disforia. Que haya generado malestar en el individuo es consecuencia del decantamiento de la racionalidad logocéntrica, autoritaria y engañosa en el ámbito de la vida ${ }^{19}$. La posibilidad de un proyecto ético universal se hundiria en el hacer cotidiano contradictorio y cínico de los individuos. Así, la práctica fundamentalista de esta racionalidad habria marginado los discursos que no se articulan con sus valores. La postmodernidad sería, entre otras causas, el resultado del surgimiento de un síntoma como consecuencia de la represión que la cultura logocéntrica produce en los individuos.

babitaciỏn en roma, y en general toda la producción ejelsoniana, desde nuestra perspectiva, se inscribiría dentro de la postmodernidad, ya que, como ló ha demostrado también Fernández Cozman, habitación en ruma "problematiza el eje de la modernidad" y revela la experiencia mutilada del hombre en la vida moderna. Es decir, la experiencia del hombre habría perdido o desintegrado su aura. Hecho que convierte la experiencia estética en un cúmulo de repeticiones y desencantamientos,

Eielson es un quínico que llega para destruir el mito del progreso moderno, un quínico que entiende la vida como una totalidad fragmentada a la que se le debe dar vuelta, atravesar de grotesco dolor y burla, incrustar las unias sucias y reír con insolencia para mostrar la dentadura disminuida de los locos.

El tono melancólico, memorioso, oculto tras un cortinaje de tristeza e impotencia, de los versos de babitación... viene a demostrarnos, como en el poema siguiente, que las cosas del mundo, de la "civilización", de la cultura formal, duelen y arrebatan al individuo su natural y perdida complacericia:

"HABERMAS, J. Teoria de la nazeon comumicalitat1 Taurus 1991 
damas y caballeros

podéis creerme ahora

amanecer es horrible

en estas condiciones

cada catre de hierro

es mi condena

cada silla de madera

una tortura

cada puerta que se cierra

una hecatombe...

pocma para destruir de inmodialo... 1976 p.202

La reacción del yo poético frente a esta situación se produce a través de una ironia patética:

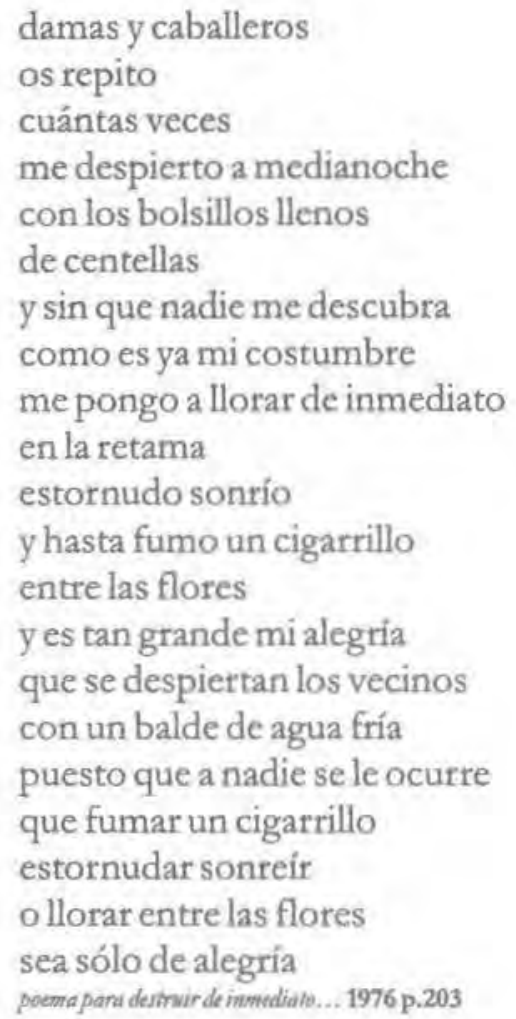

Esta reacción, sin embargo, está rompiendo con la postura seria del sufrimiento convirtiendo a éste en un absurdo que libera al yo poético trasladándolo a un ámbito en el que lo fantástico y lo grotesco germinan. El lector 
se ve envuelto entonces dentro de un cúmulo de sensaciones, como intensidades profundas, articuladas alrededor de una conciencia ética impracticable pero complaciente.

Luego, el poeta rechaza la imaginería de la modernidad, con toda su tecnología cultural, criticando las formas cómo ésta ha aniquilado la posibilidad de la verdad. El desgarro por la verdad, articulado a través de la ironía, lo relaciona directamente con el antiguo quinismo:

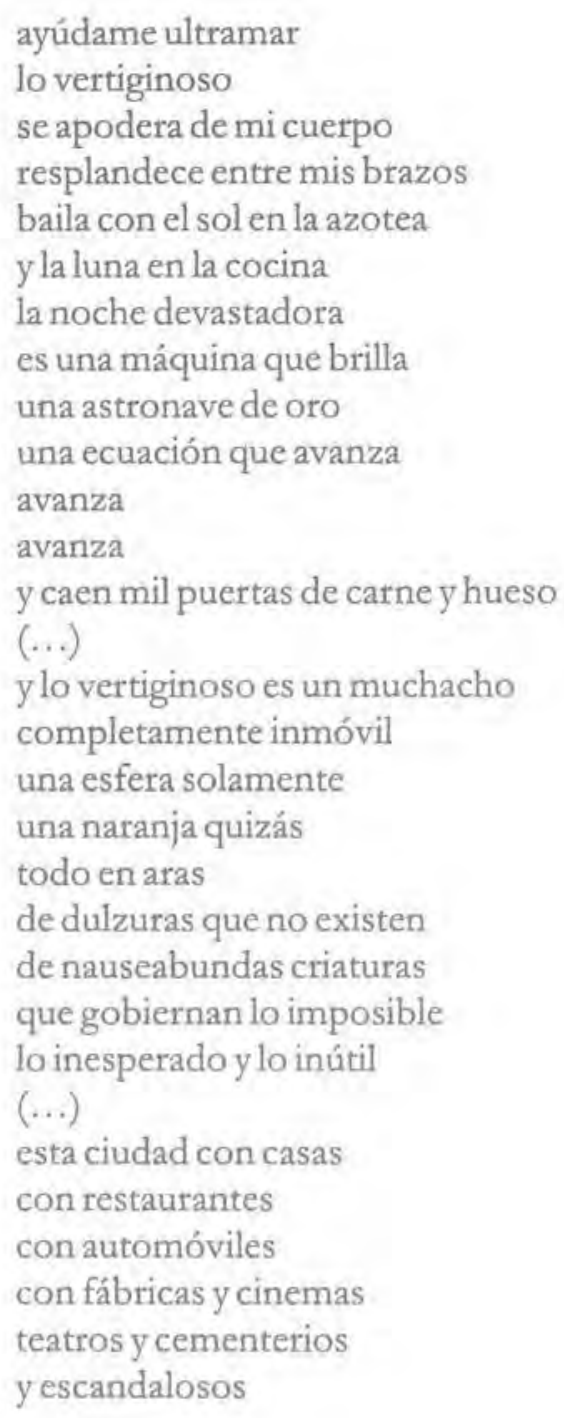


Así, la escritura de habitación ... se hallaría dentro de una mirada quínica de las cosas pues descubre el fracaso de la cultura civilizada, el fracaso de la urbe, e intenta resguardar la belleza a través de la burla, el dolor vertiginoso y la ironía. El dolor que muestra provoca un rechazo grotesco y extremo contra la condición moderna del individuo:

\author{
hay cosas que no comprendo \\ sinollorando \\ ríos de sangre por cierto \\ pero en sus manos un vaso de agua \\ $y$ entre sus ojos un ruido atroz \\ de vidrios rotos \\ además caminaba ¿recuerdas? \\ caminaba todavía \\ cuando murió es decir que se iba \\ naturalmente
}

Ahora bien, en el poema capella sixtina, se enfrenta directamente contra la formalidad del mundo moderno, en ese sentido alcanza un grado de rebeldía propio del viejo quinismo.
hay personas
correctamente vestidas de gris
con camisa y corbata ciertamente
que a duras penas son personas

Las personas son los perros que "vegetan" con alegría y placer su naturaleza, no los seres monstruosos que detentan el poder.

La escritura eilsoniana vuelca la experiencia moderna sobre una mirada que destruye el saber-hacer del individuo moderno, a través de la ruptura del lenguaje y la implantación de una estética grotesca, en la que el yo se sitúa con dolor y sin embargo con satisfacción: 
yo estúpido animal

avanzo siempre siempre

sin embargo

avanzo siempre siempre

Hasta los últimos rincones

donde se orina el sol

se orina la luna llena

se orinan los borrachos

vocifera la mierda

aúlla la soledad

criaturas que arrastráis

un solo

largo

llanto

no tengo nada

nada que ofreceros

nada en realidad

De esta manera el quinismo de Eielson recuperatía la verdad a través del horror. Es una escritura que no busca una reflexión que de razón, como una ciencia kantiana, de sí misma, segura y certera, sobre el hacer del hombre; mucho menos es un saber institucionalizado. Es, únicamente, el reproche de un ego que se fragmenta y que irrumpe contra el discurso autoritario mientras busca un lugar para recalar la sensibilidad y la belleza arrebatadas por la máquina. Detrás de esta mirada subsiste, sin duda, una visión si se quiere religiosa del hombre. Pero ese es otro asunto.

Lic. Mariano Ramírez Moreno

Universidad Católica Sedes Sapientiae

\section{BIBLIOGRAFIA}

Bürger, Peter

Teoria de la vanguardia. Madrid, Taurus 1987

Casullo, Nicolás (Compilador)

Eldebate modernidad-posmodernidad Buenos Aires: Puntosur Ed, 1991

Eielson, Jorge Eduardo.

Possía escrita. Lima: I.N.C. 1976 
Fernández Cozman, Camilo

Las buellas del aura. La poética de J.E. Eielson. Lima:

Latinoamericana Ed. 1996

Friedrich, Hugo

La estructura de la lirica moderna Barcelona Seix Barral 1974

Habermas, Jurgën.

Teoria de la razón comunicativa 1 Taurus 1991

\section{Jameson, Frederic}

El posmodernismo o la lógica cultural del capitalismo avanzado Barcelona, Paidós 1995 pp. 124.

\section{Mignolo, Walter}

"La figura del poeta en la lírica de vanguardia". Revista Iberoamericana No118-119 Enero-Junio 1982pp131-148

Pavlicic, Pavao.

"La intertextualidad moderna y posmoderna". Criterios. 30. VII-XII. La Habana 1991

Sloterdijk, Peter.

Crítica de la razón cínica 2 T. Madrid Tauros 1989 pp.280 